Cite this: J. Anal. At. Spectrom., 2013, 28, 293

Received 3rd September 2012 Accepted 7th November 2012

DOI: $10.1039 / \mathrm{c} 2 \mathrm{ja} 30251 \mathrm{a}$

www.rsc.org/jaas

\section{An automatic cryotrapping and cryofocussing system for parallel ICP-MS and EI-MS detection of volatile arsenic compounds in gaseous samplest}

\author{
Gunter Ilgen ${ }^{a}$ and Jen-How Huang*b \\ A new GC-ICP-MS/EI-MS coupling is presented, which enables the quantification and identification of \\ volatile metal and metalloid compounds in gaseous samples simultaneously. The proposed assembly is \\ fully controlled using Windows compatible software to ensure precise and reproducible analytical \\ results. The cryotrapping (CT) system is critical for sensitive and precise detection of volatile arsenic \\ compounds. Thus, the CT trap was newly designed and factors affecting CT efficiency were \\ comprehensively optimized, especially the trapping materials, trapping flow rates, heating rates and \\ trapping temperatures. Silanized glass beads $(2 \mathrm{~mm})$ as the packing material in the CT trap greatly \\ increased the trapping efficiency. A relatively high trapping flow rate $\left(200 \mathrm{~mL} \mathrm{~min}{ }^{-1}\right.$ ) gave the best \\ recoveries. An adequate heating rate (e.g. 11.3 watt $\times 360 \mathrm{~s}$ ) was required to desorb arsenic and to \\ prevent thermal decomposition. Liquid argon was demonstrated to be the most appropriate coolant, \\ since this prevented freezing of $\mathrm{O}_{2}$ and blockage of the trap. In comparison, cryofocusing (CF) was less \\ dependent on aforementioned parameters. Thick film chromatography allowed baseline separation of \\ different arsine compounds at room temperature and eliminated the interference from xenon. Analysis \\ of volatile arsenic with more complicated structures such as triethylarsine using a CT-CF technique is \\ suitable for qualitative but not for quantitative purposes due to lower stability of these compounds. The \\ resulting detection limits and RSD of arsine and methyl arsines with ICP-MS detection are 0.12-0.41 pg \\ arsenic, and $0.76-1.29 \%$, which is remarkably lower than those in previous studies.
}

\section{Introduction}

The volatile arsenic (As) plays an important role in the As biogeochemical cycle in the natural environment. ${ }^{1-3}$ The biogenic volatile As has been estimated to produce 8 times more atmospheric As than continental dust. Mestrot et al. ${ }^{1}$ measured the fluxes of arsine and methyl arsine emission from different redox fluctuated soils ranging from 29 to $2980 \mathrm{mg} \mathrm{ha}^{-1}$ per year. The global As release into the atmosphere was estimated to be $\sim 75000$ t per year and $62 \%$ of it being of natural origin. ${ }^{4}$ Biogenic As volatilisation was budgeted as the largest input at $26000 \mathrm{t}$ per year, accounting for $58 \%$ of natural emissions. The volatile As compounds are highly mobile and they may undergo longdistance transport in the atmosphere from point sources to remote sites when they are stable e.g. without the presence of UV light. ${ }^{5}$ In addition, the relevance of volatile As compounds is due to

${ }^{a}$ Chemische Analytik, BayCEER, University of Bayreuth, Dr Hans-Frisch Straße 1-3, D-95448, Bayreuth, Germany

${ }^{b}$ Institute of Environmental Geosciences, University of Basel, CH-4056 Basel, Switzerland. E-mail: jen-how.huang@unibas.ch; Fax: +41 61 2670479; Tel: +41 61 2670483

† Electronic supplementary information (ESI) available. See DOI: 10.1039/c2ja30251a its high toxicity. The volatile As compounds are with -3 oxidation state and are the most toxic among all inorganic and organic As. ${ }^{6}$

Several analytical units have been proposed for determination of volatile metal and metalloid compounds in the past, including low temperature GC-ICP-MS ${ }^{7}$ and cryotrap GC-ICPMS. ${ }^{8}$ However, the sample treatment procedures and analytical techniques based on manual cryotrapping (CT) and cryofocusing (CF) controls are usually complicated, which may potentially affect the quality of analysis and specific equipment is required such as a low temperature GC. Recently, speciation of volatile As compounds was proposed with a chemo-trap in combination with HPLC-ICP-MS. ${ }^{9}$ Normally, volatile As compounds are transformed into its oxidized form for subsequent analysis with HPLC-ICP-MS. Such a chemo-trap is especially powerful for quantifying volatile As in gaseous samples with very low As concentrations due to its potential capability of collecting a large volume of samples (up to $1500 \mathrm{~L}$ by estimation). ${ }^{1}$ The major drawbacks on chemo-traps may be the trap recovery and misinterpretation of oxidized As in the air. The speciation of volatile As is only developed for arsine and methyl arsines. Since all of the aforementioned methods may not reveal the chemical structures of analytes directly, peak identification is usually achieved by comparing the retention time with available standards $^{8,9}$ or by comparing with the theoretical boiling points. ${ }^{10}$ 
The occurrence of ethyl arsines has been verified in sewage and landfill gas, ${ }^{10}$ urging the need for an analytical tool capable of not only quantifying volatile As but also determining their chemical structures.

A GC coupled with parallel ICP-MS and EI-MS detection was proposed to determine volatile heteroatomic organic compounds and volatile As compounds. ${ }^{\mathbf{1 1}, \mathbf{1 2}}$ However, a detailed description and optimisation of the instrumental setup, especially the coldtrap system, was not elaborated well in these studies. Thus, the potential artifacts and influences of each treatment procedure on analytical results are not well understood. The strength of the GCICP-MS/EI-MS was demonstrated to be able to determine the analytes in conjunction with element specific detection of ICP-MS for high sensitivity and simultaneously identification of the chemical structure associated. However, the aforementioned coupling was not specific for speciation of volatile As and its suitability for quantifying and identifying volatile As with EI-MS has not been investigated. ${ }^{\mathbf{1 1} 12}$ In this study, we proposed a CT-CFGC-ICP-MS/EI-MS system, which is especially designed for determination of arsine and methyl arsine compounds simultaneously in one chromatogram. The CT-CF-GC-ICP-MS/EI-MS system is fully controlled by computer software, which is more user friendly as opposed to the coupling proposed in the past and enables better reproducibility in analytical results. In this study, all optimisation procedures are detailed for the first time at all with the goal to improve the technological knowledge of the CT and CF system specific for volatile As analysis.

\section{Experimental}

\section{Generation of arsine and methyl arsines}

Arsine $\left(\mathrm{AsH}_{3}\right)$, monomethylarsine $\left(\mathrm{MeAsH}_{2}\right)$, dimethylarsine $\left(\mathrm{Me}_{2} \mathrm{AsH}\right)$ and trimethylarsine $\left(\mathrm{Me}_{3} \mathrm{As}\right)$ were prepared right before each analysis by hydride generation from aqueous arsenite (As(III)) (1.0 g L ${ }^{-1}$ standard solution from Merck, Darmstadt, Germany), monomethylarsonic acid (MMA) ( $\geq 97 \%$, Argus, Vernio, Italy) and dimethylarsinic acid (DMA) ( $\geq 97 \%$, Merck, Darmstadt, Germany) and trimethylarsine oxide (TMAO) ( $\geq 97 \%$, Argus, Vernio, Italy) with sodium borohydride ( $\geq 99 \%$, Fluka, Buchs, Switzerland) in $1 \mathrm{M}$ phosphoric acid solution. Sodium borohydride solution $(3 \%, \mathrm{w} / \mathrm{w})$ was freshly prepared in $1 \% \mathrm{NaOH}(\mathrm{w} / \mathrm{w})$ before every use. The hydride generation was performed in $60 \mathrm{~mL}$ gas tight borosilicate bottles. Arsine and methyl arsines were then purged with $\mathrm{N}_{2}\left(150 \mathrm{~mL} \mathrm{~min}^{-1}\right)$ and collected in a $5 \mathrm{~L}$ Tedlar bag (SKC Inc., USA). The yield of hydride generation was close to $100 \%$, as estimated by measuring As speciation in the working solution after hydride generations. The results showed no detectable As(III), MMA, DMA and TMAO using a HPLC (Agilent 1200, Japan)-ICP-MS (Agilent 7500ce, Japan) with a PRP-X100 anionic exchange column (100 mm $\times 4.1 \mathrm{~mm}$ i.d., $10 \mu \mathrm{m}$, Hamilton, Reno, NV, USA) isocratically with $10 \mathrm{mM}$ phosphate at $\mathrm{pH} 6.0 .^{13}$

\section{Preparation of triethylarsine}

Triethylarsine ( $\mathrm{Et}_{3} \mathrm{As}$ ) (99\%) was purchased from Strem Chemicals Inc., USA. The stock solution was prepared by dissolving
$\mathrm{Et}_{3} \mathrm{As}$ in a mixture of $70 \%$ isooctane and $30 \%$ ethanol. The $\mathrm{Et}_{3} \mathrm{As}$ containing gaseous sample was prepared before each use by mixing $\mathrm{Et}_{3} \mathrm{As}$ solution with $\mathrm{N}_{2}$ in a Tedlar bag (SKC Inc., USA).

\section{Instrumentation and coupling of GC parallel with ICP-MS and EI-MS}

The proposed CT-CF-GC-ICP-MS/EI-MS system is based on a Saturn GC-EI-MS (ion trap) system (Saturn 2000, Varian, USA) and an ICP-MS (Agilent 7500ce, Japan). Parallel detection is realised with a post-column Y split (Universal Y Presstight Connector, Restek, USA) inside the GC oven, connecting the analytical column (30 m, $0.32 \mathrm{~mm}$ ID, Rxi-1MS, Restek, USA) with: (1) a methyl deactivated capillary line (2 m length, $0.25 \mathrm{~mm}$ ID, $0.363 \mathrm{~mm}$ OD, SGE, Australia) and a perfluoroalkoxy (PFA) transfer line (1.5 m length, $0.8 \mathrm{~mm}$ ID, $1.58 \mathrm{~mm}$ OD, Roth, Germany) to ICP-MS and (2) two methyl deactivated capillary lines to EI-MS (7 cm length, $0.11 \mathrm{~mm}$ ID, $0.31 \mathrm{~mm}$ OD and $80 \mathrm{~cm}$ length, $0.17 \mathrm{~mm}$ ID, $0.3 \mathrm{~mm}$ OD, both SGE, Australia) (Fig. 1 and more details in the ESI, Fig. S1 $\dagger$ ). The design with two separate columns on the path to EI-MS enables the regulation of flux split between ICP-MS and EI-MS. The longer and thicker capillary serves as a transfer line between the analytical column and EI-MS. The fine and shorter capillary is responsible for regulating the flux. Using the fine capillary simultaneously as the flux regulator and transfer line is infeasible because at least an $80 \mathrm{~cm}$ long capillary is required to connect GC and EI-MS and a fine capillary in such a length will not allow any gas flow to EI-MS. The small diameter is necessary to compensate for the pressure difference between EI-MS (vacuum) and ICP-MS (normal atmospheric pressure). The original GC-EI-MS construction allows analytes to transfer into an EI-MS without leaving the GC oven. A $\mathrm{T}$ piece $(1.58 \mathrm{~mm}$, Swagelok, USA) inside the GC oven allows a mixture of Ar for further transfer of analytes toward the torch of ICP-MS with the transfer line. All optimised parameters of ICP-MS and EI-MS are summarised in Table 1.

\section{Gas chromatography program}

An analytical capillary column (30 m, $0.32 \mathrm{~mm}$ ID, Rxi-1MS, Restek, USA) with $4 \mu \mathrm{m}$ film thickness is installed in a GC to separate analytes with low boiling points (e.g. -55 and $2{ }^{\circ} \mathrm{C}$ for $\mathrm{AsH}_{3}$ and $\mathrm{MeAsH}_{2}$, respectively) without additional cooling. The oven temperature rises from 40 to $120{ }^{\circ} \mathrm{C}$ at a rate of $15{ }^{\circ} \mathrm{C}$ $\min ^{-1}$, then increases from 120 to $240{ }^{\circ} \mathrm{C}$ at a rate of $50{ }^{\circ} \mathrm{C}$ $\min ^{-1}$ and holds at $240{ }^{\circ} \mathrm{C}$ for one minute. Helium (He) is used as a carrier gas. The flow rate is adjusted to $5.5 \mathrm{~mL} \mathrm{~min}{ }^{-1}$, whereas the mass flow meter before CT-CF indicated $3.2 \mathrm{~mL}$ $\min ^{-1}$. In comparison, $1.7 \mathrm{~mL} \mathrm{~min}^{-1}$ was measured before the inlet to ICP-MS, which is $\sim 50 \%$ of the total real flow rate.

\section{Controlling software}

Self-designed Windows compatible software (Cryotrap Version 6.0, Elektronikwerkstatt - Zentrale Technik, University of Bayreuth, Germany) was responsible for the control of whole CT-CF-GC-ICP-MS/EI-MS coupling, including the mass flow controller (MFC) (sample uptake rates and volumes), the action of 6 valve port, 2 purge and trap systems (trap dipping and 


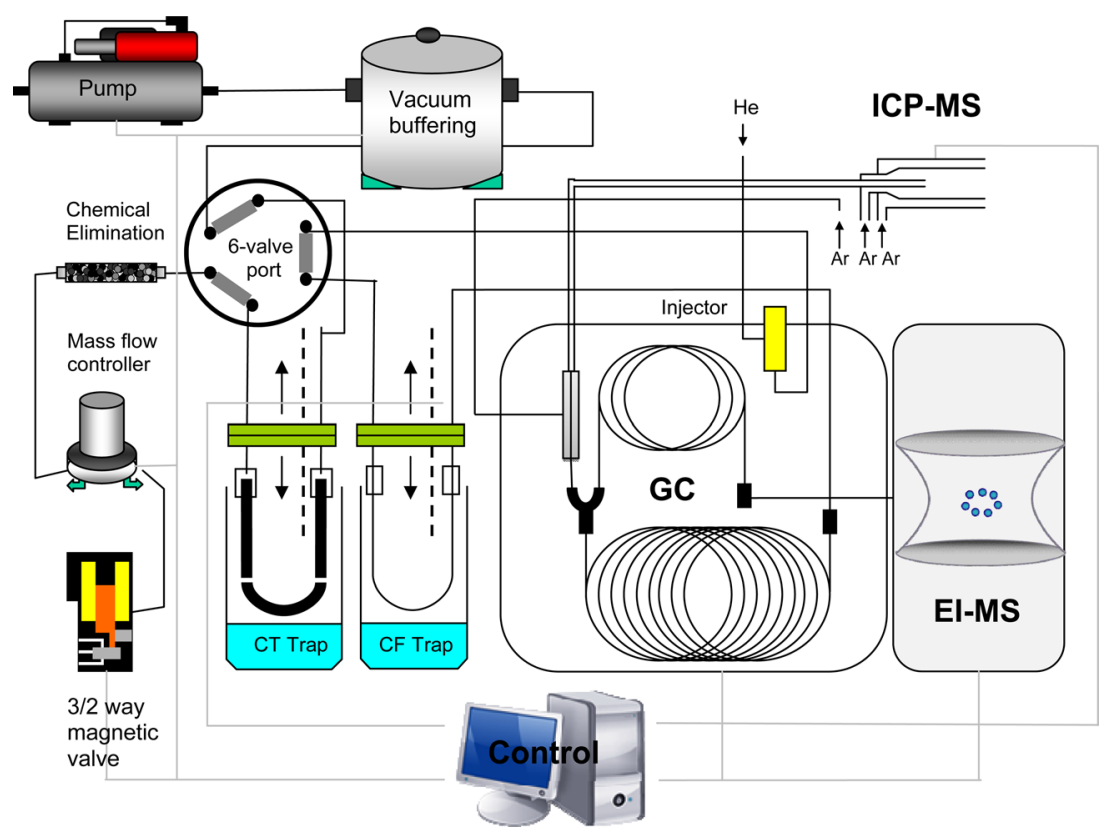

Fig. 1 Schematic presentation of the proposed automatic CT-CF-GC-ICP-MS/EI-MS coupling. Black lines show the connection between each component and grey lines show the connection of each component to the automatic control system.

arising rates and heating rates) and He flushing before and after analysis. The user friendly interface informs clearly the status of sample uptakes, the working conditions of the vacuum pump and the position and heating conditions of both cryotraps. Additionally, correction of retention time is performed with controlling software to compensate the difference of retention time $(\sim 3 \mathrm{~s})$ in ICP-MS and EI-MS chromatograms due to the difference in travel pathways.

\section{Results and discussion}

Table 1 summarizes the parameters optimized for the proposed CT-CF-GC-ICP-MS/EI-MS. The development and optimisation of components involved are described as the following:

\section{Mass flow control system (MFC)}

The mass flow controller (MFC) (F-201D-FAC-11-E, Bronkhorst, Ruurlo, The Netherlands) was calibrated with air at $-700 \mathrm{mbar}$ pressure, allowing electronic quantification of the sample volume and flow rate. The precise quantification of the sample volume is indispensable for accurate determination of the analyte concentrations. The MFC system was installed between the sample and the chemical elimination unit. The MFC installed after chemical elimination would strongly affect the quantification of the sample volume due to the change in gas composition. Calibration of the gas volume was conducted with gas containing arsine and methyl arsine standards approaching to the sample matrix.

\section{Chemical elimination}

Water, $\mathrm{CO}_{2}$ and $\mathrm{H}_{2} \mathrm{~S}$ in different types of gaseous samples were eliminated with $2.5 \mathrm{~g}$ granulated $\mathrm{NaOH}$ (0.8-1.6 mm, Merck,
Darmstadt, Germany) packed in a glass tube $(25 \mathrm{~cm}, 5 \mathrm{~mm}$ ID, 8 $\mathrm{mm}$ OD). The chemical elimination unit was installed after the MFC and before the 6 valve port (Fig. 1). Both our preliminary investigation and literature reports have all shown the effectiveness of granulated $\mathrm{NaOH}$ for this purpose, despite potentially slight losses of arsine compounds due to adsorption and neutralisation. ${ }^{14}$ Granulated $\mathrm{NaOH}$ has the advantage over other materials because its consumption is visible, since white and black colouring appears by $\mathrm{Na}_{2} \mathrm{CO}_{3}$ and $\mathrm{H}_{2} \mathrm{O}$, respectively. The $\mathrm{NaOH}$ granulates were replaced regularly or directly after measurement of samples with large amounts of water and $\mathrm{CO}_{2}$ to avoid blockage of the $\mathrm{NaOH}$ trap. In comparison, the use of $\mathrm{Mg}\left(\mathrm{ClO}_{4}\right)_{2}$ (85\%, 1-4 mm, Merck, Germany) and a Nafion membrane dryer (Perma Pure Inc., Toms River, NJ, USA, Model MD-110-12FP) contributed to a complete loss of $\mathrm{Me}_{3} \mathrm{As}, \mathrm{Me}_{2} \mathrm{AsH}$ and $\mathrm{AsH}_{3}$ after chemical elimination, as revealed in our preliminary investigation. A complete loss of $\mathrm{Me}_{3} \mathrm{As}$ and a 19$66 \%$ loss of $\mathrm{Me}_{2} \mathrm{AsH}$ were found upon passage through a Nafion membrane dryer. ${ }^{15}$ Moreover, $\mathrm{Me}_{3} \mathrm{As}, \mathrm{Me}_{2} \mathrm{AsH}$ and $\mathrm{MeAsH}_{2}$ could not be detected after treatment with molecular sieve, whereas the treatment with lead acetate seemed to reduce the recovery of $\mathrm{AsH}_{3} \cdot{ }^{16}$

\section{Automatic cryotrapping and cryofocussing system (CT-CF)}

The software controlled CT and CF system is responsible for the sample pre-concentration. The fully automatized CT-CF system simplifies the analytical procedures and improves the reproducibility. Silcostainless steel with sulfinert ${ }^{\circledR}$ surface treatment (Restek, USA) by bonding an inert silica layer was used either as the trap (CT trap) or as the outer tubing of a fused silica capillary (CF trap) to prevent from sorption of analytes and to avoid capillary break during purge and trap procedures. 
Table 1 Operating conditions for the CT-CF-GC-ICP-MS/EI-MS set-up

\section{Cryotrapping (CT Trap)}

Trap tubing

Sampling flow rate

Cryogenic trapping temperature $-186^{\circ} \mathrm{C}$ (liquid $\mathrm{Ar}$ )

Trap dipping and arising speed $7.5 \mathrm{~cm} \mathrm{~s}^{-1}$

Desorption heating rate/max.

temperature

Desorption He flow rate

$3.2 \mathrm{~mL} \min ^{-1}$

Cryofocusing (CF Trap)

Trap capillary/tubing

Cryofocusing temperature Trap dipping and arising speed Desorption heating rate/max. temperature

Desorption He flow rate

\section{Gas chromatography}

Column

Carrier He flow rate

Temperature range

Fused silica capillary $(60 \mathrm{~cm}$ length, $0.32 \mathrm{~mm}$ ID, methyl deactivated, SGE, Australia) encompassed in silcostainless steel tubing $(60 \mathrm{~cm}$ length, $1.02 \mathrm{~mm}$ ID and

$1.59 \mathrm{~mm}$ OD, Restek, USA)

$-195.8{ }^{\circ} \mathrm{C}$ (liquid $\mathrm{N}_{2}$ )

$7.5 \mathrm{~cm} \mathrm{~s}^{-1}$

50 watt $\times 50 \mathrm{~s} / 70^{\circ} \mathrm{C}$

$3.2 \mathrm{~mL} \min ^{-1}$

Fused silica capillary (30 m length, $0.32 \mathrm{~mm}$ ID, film thickness $4 \mu \mathrm{m}$ ) (Rxi-1MS, Restek, USA)

$3.2 \mathrm{~mL} \mathrm{~min}^{-1}$ $40-240{ }^{\circ} \mathrm{C}$

\section{ICP-MS unit}

Plasma gas

Auxiliary gas

Carrier gas

Make up gas

Optional gas

RF power

Sampling depth

Measured isotope

$15 \mathrm{~L} \mathrm{~min}^{-1}$
$0.85 \mathrm{~L} \mathrm{~min}^{-1}$
$0.15 \mathrm{~L} \mathrm{~min}^{-1}$
$0.15 \mathrm{~L} \mathrm{~min}^{-1}$
$0.0225 \mathrm{~L} \mathrm{~min}^{-1}\left(\mathrm{Ar} 90 \%, \mathrm{O}_{2} 10 \%\right)$
$1600 \mathrm{~W}$
$6.8 \mathrm{~mm}$
${ }^{75} \mathrm{As}$

EI-MS unit

Mass window (scan)

Transfer line temperature

Trap temperature

$m / z 70-200$

$180{ }^{\circ} \mathrm{C}$

$180^{\circ} \mathrm{C}$

\section{Cryotrapping (CT)}

The cryotrapping efficiency affected largely the analytical precision and sensitivity of each arsine compound. The trapping efficiency depends on the trapping material and tubing, temperature of a cold trap, boiling points of analytes, flow rate of sampling and heating rate. The details are described in the following paragraphs. Moreover, the sample matrix may interfere with trapping by e.g. blocking the tubing.

TRAPPING MATERIALS AND TUBING. Trapping materials and tubing were expected to have a substantial influence on CT efficiency due to the potential surface interaction of tubing and packing materials with volatile As compounds. Due to the relatively large tubing for the CT trap, there is a potential loss of

volatile As during trapping. The trapping efficiency of all arsine compounds increased remarkably by filling silanized glass beads $(2 \mathrm{~mm}$, Roth, Germany, silanized with dichlorodimethylsilane (Sigma-Aldrich, Germany) in 5\% toluene (Merck, Germany)) in the sulfinert deactivated stainless steel tubing ( $65 \mathrm{~cm}$ length, $5.33 \mathrm{~mm}$ ID, $6.35 \mathrm{~mm}$ OD, Restek, USA) (Fig. 2a). Apparently, silanized glass beads provided larger surface area available for adsorption, leading to higher trapping efficiency than tubing without glass beads. Specifically, the increase of trapping efficiency of all methyl arsines $(\sim 270 \%$ increase) was much larger than $\mathrm{AsH}_{3}(\sim 70 \%$ increase). This reflects higher affinity of methyl arsines to silanized glass beads than $\mathrm{AsH}_{3}$ due to organic interactions. Thus, the proposed CT trap containing silanized glass enhanced the cryotrapping efficiency via additional interaction of arsenic compounds with the stationary phase on the glass bead.

The trapping efficiency of methyl arsines decreased by changing outer tubing to quartz or glass (Fig. 2b). In the case of quartz, the trapping efficiency of $\mathrm{MeAsH}_{2}$ and $\mathrm{Me}_{2} \mathrm{AsH}$ reduced $\sim 50 \%$ and $\mathrm{Me}_{3} \mathrm{As}$ decreased $\sim 70 \%$. Although the trapping efficiency of $\mathrm{MeAsH}_{2}$ also decreased $\sim 50 \%$, the decreases for $\mathrm{Me}_{2} \mathrm{AsH}$ and $\mathrm{Me}_{3} \mathrm{As}$ were significantly higher ( $\sim 75 \%$ and $\sim 90 \%$, respectively) with glass outer tubing. The lower recovery of higher methylated arsines may be explained with their lower affinity to the polar surface of quartz and glass. The experimental result here further indicates that the material of the outer tubing affected substantially the trapping efficiency given a similar surface area between e.g. the quartz and glass tubing $\left(81.6 \mathrm{~cm}^{2}\right)\left(65 \mathrm{~cm}\right.$ long, $4 \mathrm{~mm}$ i.d.) and glass beads $\left(81.7 \mathrm{~cm}^{2}\right)$.

TRAPPING FLOW RATES. We examined the influence of a trapping flow rate of samples on the recovery rate of volatile As from 25 to $200 \mathrm{~mL} \mathrm{~min}^{-1}$ (Fig. 2c). Surprisingly, low trapping rates resulted in low recovery rate of $\mathrm{AsH}_{3}$ and $\mathrm{MeAsH}_{2}$. The recovery of arsine compounds varied little with trapping flow rates over $100 \mathrm{~mL} \mathrm{~min}^{-1}$.

TRAPPING TEMPERATURES. Although the boiling point of $\mathrm{AsH}_{3}$ is $-55^{\circ} \mathrm{C}$, much lower temperature in the CT trap was essential to trap $\mathrm{AsH}_{3}$. The trapping temperature in the $\mathrm{CT}$ trap ranged mostly from -80 to $-186^{\circ} \mathrm{C}$ in the previous studies. ${ }^{8,17,18}$ This was usually achieved by mixing liquid $\mathrm{N}_{2}$ and organic solvents. However, such mixtures were not under our consideration because of laboratory safety. Another disadvantage was the formation of highly viscous liquid at low temperature, which stayed on the outer tubing and slowed down the increase of the tubing temperature by heating. Liquid $\mathrm{N}_{2}$ could be an alternative coolant for the CT trap. ${ }^{19}$ However, the low boiling point $\left(-195.8^{\circ} \mathrm{C}\right)$ of liquid $\mathrm{N}_{2}$ might trap $\mathrm{O}_{2}$ (boiling point $-182.95{ }^{\circ} \mathrm{C}$ ) in samples and consequently influence the analysis. In this sense, the use of liquid $\mathrm{N}_{2}$ as the coolant for CT was demonstrated to be suitable for the analysis of volatile As spiked in $\mathrm{N}_{2}$ but not feasible for the analysis of volatile As spiked in synthetic air (Fig. 2d). We observed remarkable decreases of the flow rate during transferring air based samples via a CT trap cooled by liquid $\mathrm{N}_{2}$. Apparently, the condensed $\mathrm{O}_{2}$ blocked the trap, leading to a complete loss of all As species (Fig. 2d). In contrast, the use of liquid Ar as the coolant did not contribute to any significant loss of As spiked in the synthetic air despite the higher cost than that of liquid $\mathrm{N}_{2}$. The higher boiling 

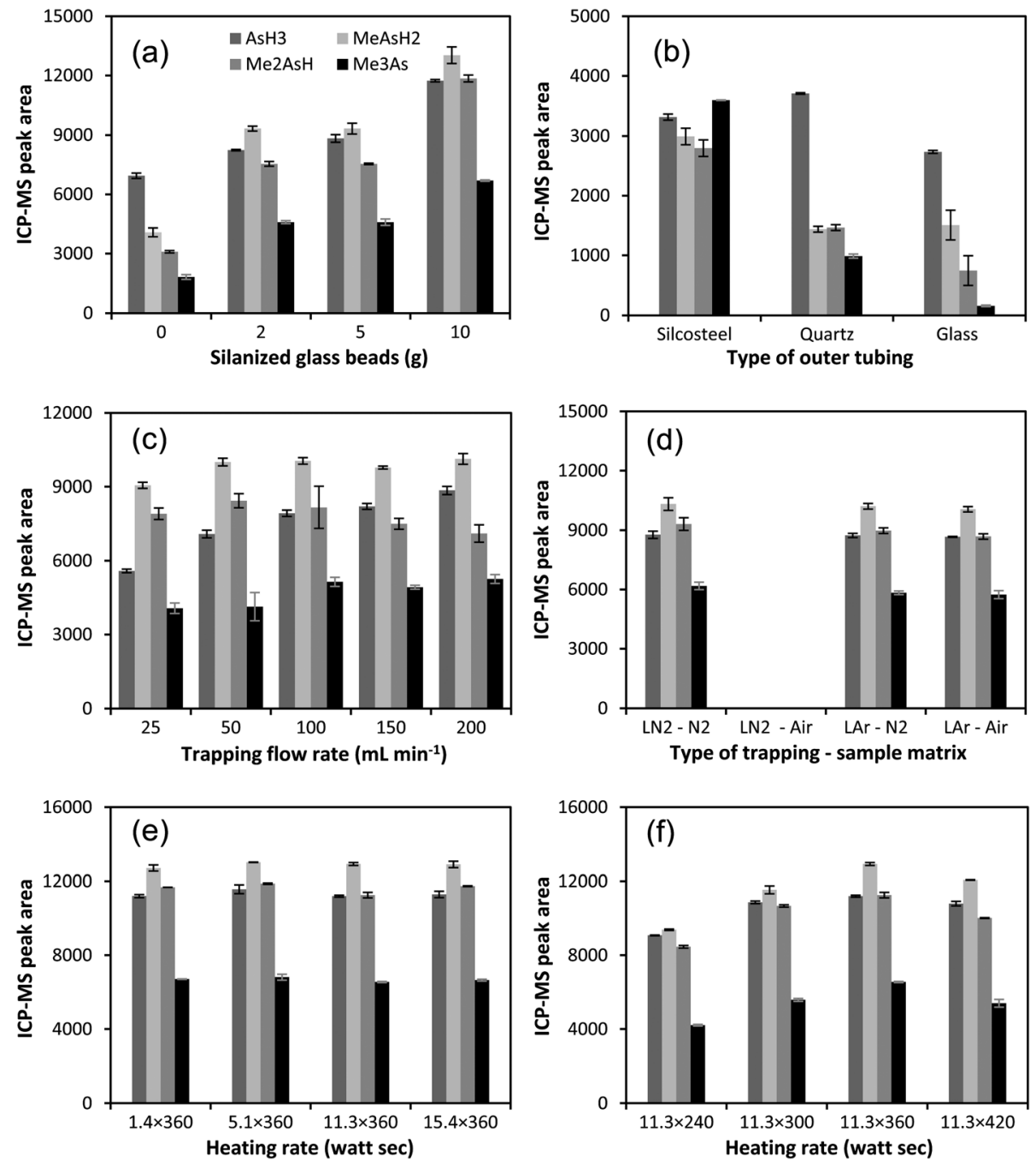

Fig. 2 ICP-MS based peak areas of arsine $\left(\mathrm{AsH}_{3}\right)$, monomethylarsine $(\mathrm{MeAsH})$, dimethylarsine $\left(\mathrm{Me}_{2} \mathrm{AsH}\right)$ and trimethylarsine $\left(\mathrm{Me}{ }_{3} \mathrm{As}\right)$ with the cryotrap containing (a) different amounts of silanized glass beads, (b) different materials of outer tubing, or running with (c) different trapping flow rates, (d) different types of trapping and sample matrices, (e) various heating powers and ( $f$ ) various heating times. If not else mentioned, the cryotrapping unit consisted of silcosteel outer tubing filled with $10 \mathrm{~g}$ silanized glass beads using liquid $\mathrm{N}_{2}$. The sample trapping rate was $200 \mathrm{~mL} \mathrm{~min}{ }^{-1}$. The heating rate was 11.3 watt $\times 360 \mathrm{~s}$. $100 \mathrm{pg}$ As of each arsine compound was prepared in $1000 \mathrm{~mL}$ of $\mathrm{N}_{2}$. Mean values and standard deviations of 3 replicates are shown.

point of $\operatorname{Ar}\left(-186.0^{\circ} \mathrm{C}\right)$ largely reduces the extent of $\mathrm{O}_{2}$ condensation in the CT trap.

The aforementioned results highlight the potential limitation of the proposed CT-CF-GC-ICP-MS/EI-MS coupling for analysing samples with a large volume. Although the problem with $\mathrm{O}_{2}$ condensation may be solved by using liquid $\mathrm{Ar}$, large amounts of other matrices such as $\mathrm{H}_{2} \mathrm{O}, \mathrm{CO}_{2}$ and $\mathrm{H}_{2} \mathrm{~S}$ may interfere with the efficiency of chemical elimination by $\mathrm{NaOH}$ solids. Thus, the proposed coupling may not be suitable for samples with very low As concentrations, where a large sample volume is required for accurate analysis. In real samples, $\mathrm{CO}_{2}$ and $\mathrm{H}_{2} \mathrm{O}$ are often causing problems.

HEATING RATES. The optimal heating allows analytes to vaporise efficiently but not to decompose thermally. We have verified the influence of the heating rate on the recovery of different arsine compounds by changing the heating power and time. The recovery of arsine compounds was generally less dependent on the heating power (Fig. 2e). In comparison, the heating time length showed remarkable effects on recovery of arsine compounds (Fig. 2f). At a constant heating power of 11.3 watt, the highest recovery was achieved at 360 seconds of heating. The recovery rate of arsine compounds decreased with either increasing or decreasing heating time length. The shorter heating time length may not allow desorption of arsine compounds from tubing and glass beads completely, whereas heating for a longer time may lead to thermal decomposition of arsine compounds. Running a blank after measurements with low recovery showed no residual As compounds. Except thermal decomposition, He flushing before and after analysis seemed to eliminate residual As compounds effectively.

\section{Cryofocussing (CF)}

The goal of a CF trap is to focus the analytes into a much smaller volume as compared to a CT trap. This approach can reduce the GC peak width. For this purpose, a methyl deactivated fused 
silica capillary (5 m length, $0.32 \mathrm{~mm}$ ID, $0.43 \mathrm{~mm}$ OD, SGE, Australia) was connected from a 6 valve port to the GC (as CF Trap) and stretched around $0.6 \mathrm{~m}$ long inside silcostainless steel tubing (1.02 mm ID, $1.59 \mathrm{~mm}$ OD, Restek, USA) serving as a CF trap. Cryofocusing was achieved at $-195.8^{\circ} \mathrm{C}$ using liquid $\mathrm{N}_{2}$ as the coolant. The transfer of analytes from the CT trap to the CF trap was carried out by purging with $3.2 \mathrm{~mL} \mathrm{~min}^{-1} \mathrm{He}$ after heating. This process took 6 minutes due to the large volume difference between the CT trap (around $12 \mathrm{~cm}^{3}$ with glass beads) and the CF trap $\left(0.08 \mathrm{~cm}^{3}\right)$. A larger volume of He than that of the CT trap (around 1.6 times) was introduced to ensure the complete transfer of analytes from the CT trap to the CF trap (ESI, Fig. S2 $\dagger$ ). Further transfer of analytes from the CF trap to GC was achieved by heating the CF trap at 50 Watts for 50 seconds and then purging $\mathrm{He}$ at $3.2 \mathrm{~mL} \mathrm{~min}^{-1}$. Notice that heating CF was not necessary but could keep the peak retention time constant. A higher heating power and a shorter heating time were applied here to desorb volatile As compounds rapidly and were intended to keep the peak width as small as possible. However, higher heating rates were not able to further improve the chromatography, as indicated by our preliminary experiments (ESI, Fig. S3†).

\section{Transfer line between GC and ICP-MS}

Transfer line is responsible for transferring analytes to the torch of ICP-MS. Transfer lines between GC and ICP-MS were usually heated to avoid the deposit of analytes during transport. ${ }^{\mathbf{1 1}, \mathbf{1 7}}$ Heating transfer line is not necessary for analysis of volatile As. Mixing the analyte with Ar after chromatographic separation lowers mixture's boiling points. ${ }^{17,20}$ Our investigation also indicated that transfer line heating does not affect the determination of arsine and methyl arsines (ESI, Fig. S4†).

\section{Transfer line between GC and EI-MS}

The temperature of the transfer line between GC and EI-MS moderately affected the analysis of arsine compounds with EIMS. Generally, the recovery of each arsine compound increased with increasing temperature from 120 to $200{ }^{\circ} \mathrm{C}$ (Fig. 3). Since the ion trap temperature for EI-MS was $180{ }^{\circ} \mathrm{C}$, the temperature of the transfer line between the GC unit and EI-MS was adjusted to $180{ }^{\circ} \mathrm{C}$.

\section{ICP-MS unit}

In order to avoid peak broadening, the carrier gas Ar at $150 \mathrm{~mL}$ $\min ^{-1}$ of ICP-MS was allowed to pass through immediately after the split of the GC flow via a T-piece (1.58 mm, Swagelok, USA). Another T-piece $(1.58 \mathrm{~mm}$, Swagelok, USA) was installed before the plasma torch to mix with the make-up and optional gas for the ICP-MS to maximise the instrumental sensitivity. Meanwhile, the gas with an optional flux was able to remove the carbon deposit on the cones of ICP-MS.

\section{Analysis of arsines with more complicated structures}

We examined triethylarsine ( $\left.\mathrm{Et}_{3} \mathrm{As}\right)$ in an attempt to measure arsine compounds with high boiling points. However, the

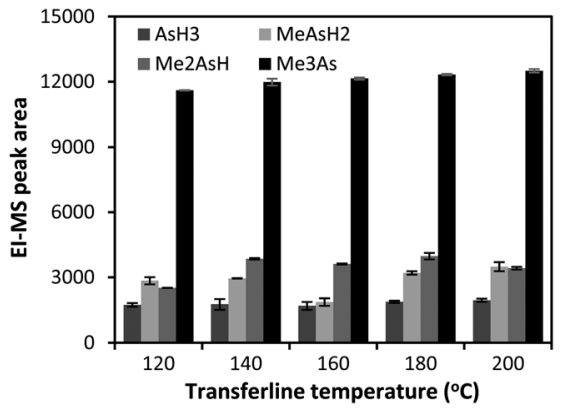

Fig. 3 El-MS based peak areas of arsine $\left(\mathrm{AsH}_{3}\right)$, monomethylarsine $\left(\mathrm{MeAsH}_{2}\right)$, dimethylarsine $\left(\mathrm{Me}_{2} \mathrm{AsH}\right)$ and trimethylarsine $\left(\mathrm{Me}_{3} \mathrm{As}\right)$ at different temperatures of transfer line between GC and El-MS. 100 pg As of each arsine compound in $1000 \mathrm{~mL}$ of $\mathrm{N}_{2}$. Mean values and standard deviations of 3 replicates are shown.

recovery of $\mathrm{Et}_{3} \mathrm{As}$ is always lower than arsine and methyl arsines probably due to the higher boiling point and instability. In addition, we usually observed a lower recovery rate of $\mathrm{Et}_{3} \mathrm{As}$ at higher heating rates by CT (ESI, Fig. S5†). Rapid heating may cause local overheating and accelerate decomposition of $\mathrm{Et}_{3} \mathrm{As}$. Jakob et al. $(2010)^{5}$ demonstrated the higher stability of arsine than methyl arsines with and without UV irradiation. This is probably attributed to the lower stability of the As-C bond (262 $\left.\mathrm{kJ} \mathrm{mol}^{-1}\right)$ in comparison to the As- $\mathrm{H}$ bond $\left(352 \mathrm{~kJ} \mathrm{~mol}^{-1}\right) .{ }^{5} \mathrm{On}$ the other hand, strong deformation and broadening of the $\mathrm{Et}_{3} \mathrm{As}$ peak was observed with low heating rates (ESI, Fig. S5†). This made the $\mathrm{Et}_{3} \mathrm{As}$ determination difficult. The boiling point of $\mathrm{Et}_{3} \mathrm{As}\left(140-147^{\circ} \mathrm{C}\right)$ is much higher than arsine $(-45$ to $\left.-55{ }^{\circ} \mathrm{C}\right)$ and all methylarsines $\left(<57{ }^{\circ} \mathrm{C}\right) .{ }^{10}$ Thus, $\mathrm{Et}_{3} \mathrm{As}$ apparently desorbed much slower from the capillary than the other volatile As compounds with lower molecular weights. In summary, the determination of $\mathrm{Et}_{3} \mathrm{As}$ or arsine compounds with complicated organic parts using the proposed coupling is more qualitative than quantitative.

\section{Chromatographic performance}

Fig. 4 shows the standard EI-MS and ICP-MS chromatograms of volatile As. Good recovery is obtained for all As compounds through ICP-MS. The presence of Xe interfered with the detection of $\mathrm{AsH}_{3}$ with EI-MS (ESI, Fig. S6 and S7†). Such interference was not able to be eliminated by the CT and CF system. Chromatographic separation is then required for $\mathrm{AsH}_{3}$ detection with EI-MS. This can be implemented by starting the gas chromatography at low temperature through a thin film column. Thus, an attempt was made to separate Xe and $\mathrm{AsH}_{3}$ peaks with a thin film column (film thickness 0.25 and $1 \mu \mathrm{m}$ ) by starting gas chromatography at $10^{\circ} \mathrm{C}$, which was achieved with liquid $\mathrm{CO}_{2}$. However, it was still not able to separate Xe and $\mathrm{AsH}_{3}$ peaks. A simple and effective solution is to use thick film column. Using a nonpolar thick film column (30 m length, 0.32 mm ID, film thickness $4 \mu \mathrm{m}, 100 \%$ dimethyl polysiloxane, Restek, USA), good separation between Xe and $\mathrm{AsH}_{3}$ is achieved in a chromatogram starting at $40{ }^{\circ} \mathrm{C}$. This makes the measurement easy in summer time, which the room temperature often reaches up to over $30{ }^{\circ} \mathrm{C}$. 

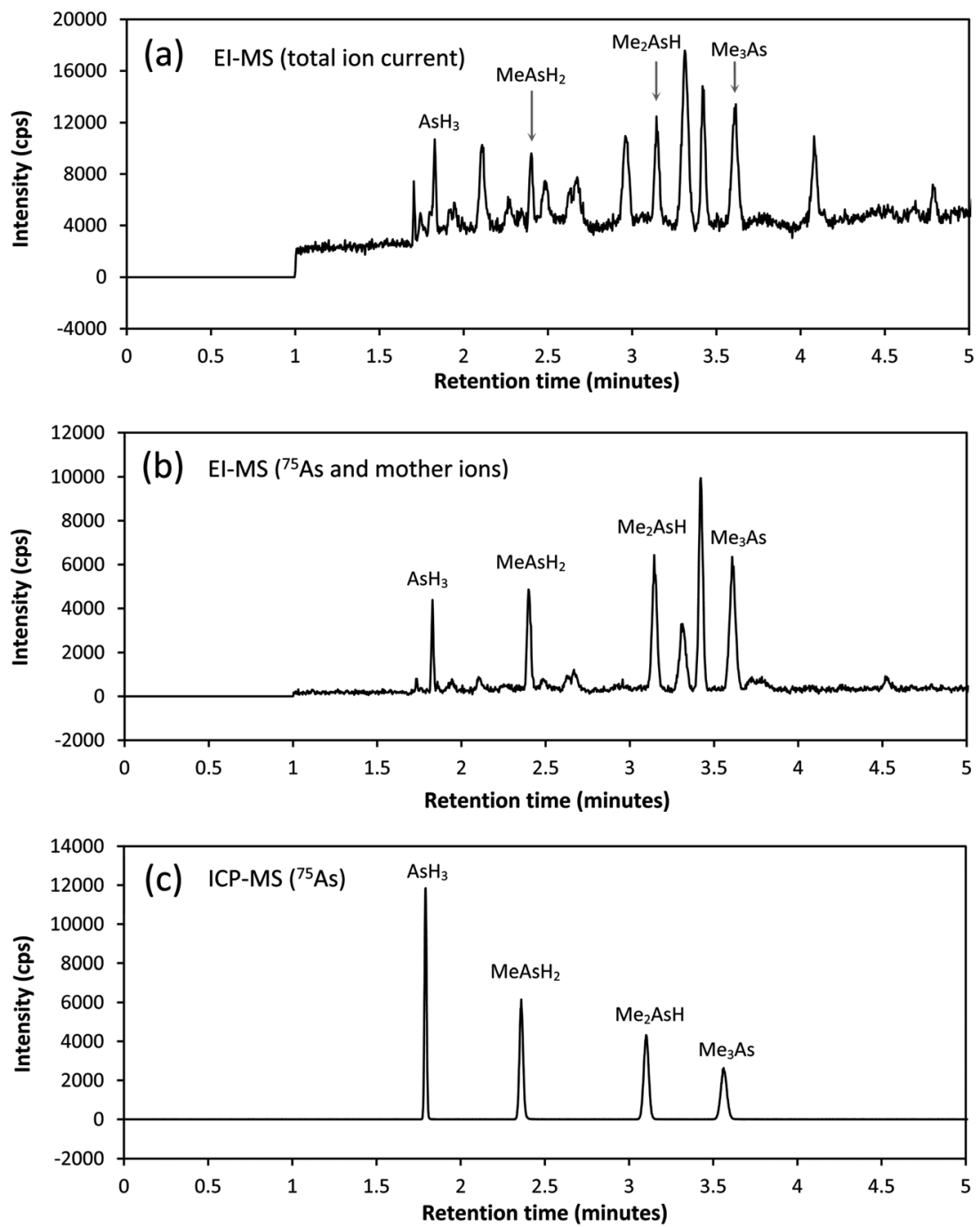

Fig. 4 Chromatograms of arsine and methyl arsines monitored on an EI-MS by (a) total ion current (TIC) and (b) selected ions $\left({ }^{75}\right.$ As and mother ions) and on an ICP-MS by (c) ${ }^{75} \mathrm{As}$. The corresponding mass spectrum of each arsine compound is shown in the ESI, Fig. S9. +

\section{Analytical performance}

In general, ICP-MS provides better analytical performance than EI-MS with the proposed CT-CF-GC-ICP-MS/EI-MS coupling. The detection based on ICP-MS provides more sensitivity and higher reproducibility than EI-MS does (Table 2). Calculation based on DIN 23645 (ref. 21) shows that LODs of arsines are 0.12-0.41 pg As for ICP-MS and 6.8-11 pg As for EI-MS. Meanwhile, LOQs of analyses on an EI-MS (22-31 pg As) were remarkably higher than those on ICP-MS (0.59-1.41 pg As). Measurements of $50 \mathrm{pg}$ As of each standard gave relative

Table 2 Limit of detection (LOD) and quantification (LOQ) (in pg As), correlation coefficient of the calibration curve $\left(R^{2}\right)$ and relative standard deviation (RSD) of analyses using the proposed CT-CF-GC-ICP-MS/EI-MS coupling $(n=5)^{a}$

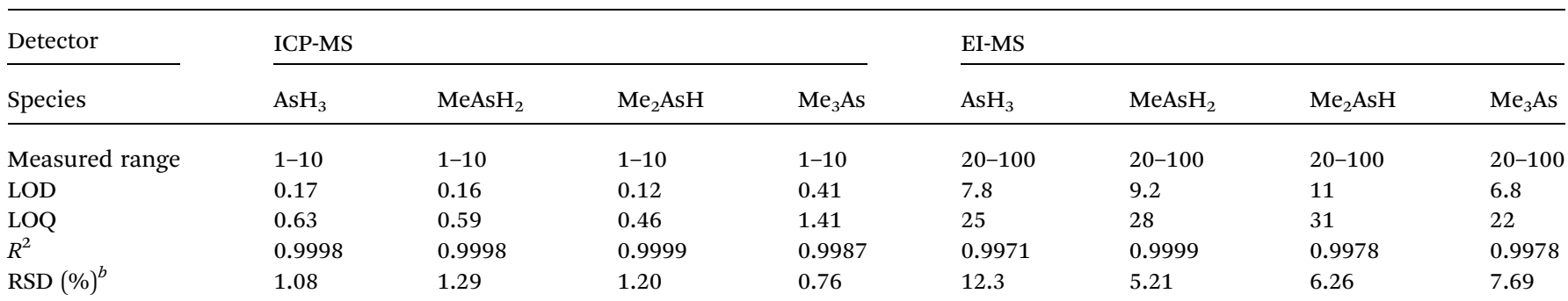

${ }^{a}$ Peak areas from ICP-MS and EI-MS chromatograms were taken for quantification. LOD and LOQ were estimated with DNITEST at a 5\% level of significance according to DIN32645. ${ }^{21} b$ Based on measurements of $50 \mathrm{pg}$ As arsine and methyl arsines with 5 replicates. 
Table 3 Concentrations of arsine and methyl arsines in headspace of wetland soil incubations at $15^{\circ} \mathrm{C}$ for 9 days with and without additional spiking of As(III) (250 $\mu \mathrm{g}$ As) based on ICP-MS quantification. The incubation was achieved with $60 \mathrm{~g}$ of histosol (sampled in Fichtelgebirge, NE-Bavaria, Germany) with a water content of $93 \%$ w/w overflooded with $100 \mathrm{~mL}$ artificial rainwater

\begin{tabular}{|c|c|c|c|c|}
\hline & $\begin{array}{l}\mathrm{AsH}_{3} \\
\left(\mu \mathrm{g} \mathrm{As} \mathrm{m}{ }^{-3}\right)\end{array}$ & 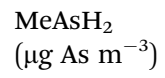 & 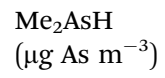 & $\begin{array}{l}\mathrm{Me}_{3} \mathrm{As} \\
\left(\mu \mathrm{g} \mathrm{As} \mathrm{m}{ }^{-3}\right)\end{array}$ \\
\hline Wetland soil ${ }^{a}$ & 2.43 & 0.57 & $<\mathrm{DL}$ & 1.22 \\
\hline
\end{tabular}

${ }^{a}$ Corresponding ICP-MS and EI-MS chromatograms are shown in the ESI, Fig. S8.

standard deviations (RSD) $<1.3 \%$ with ICP-MS and $<7.7 \%$ with EI-MS. As a comparison, a recently proposed coupling based on a packed cotton column coupled with atomic fluorescence spectrometry has a detection limit between 2.5 and $11 \mathrm{pg}$ As and a RSD of $3.2-4.9 \%$ for arsine and methyl arsines. ${ }^{22}$ Thus, our newly developed CT-CF-GC-ICP-MS/EI-MS coupling provides comparably higher sensitivity and reproducibility for the analysis of volatile As compounds.

\section{Applicability}

Analysing the headspace of wetland soil incubations with and without additional spiking $0.25 \mathrm{mg}$ As as As(III) showed the validation of the proposed CT-CF-GC-ICP-MS/EI-MS coupling for the real environmental samples. The concentrations of $\mathrm{MeAsH}_{2}$ and $\mathrm{Me}_{3} \mathrm{As}$ were around $1 \mu \mathrm{g} \mathrm{As} \mathrm{m}{ }^{-3}$, and no $\mathrm{Me}_{2} \mathrm{AsH}$ was detectable (Table 3 ). Arsine was the predominant volatile As and its concentration increased from 2.43 to $13.03 \mu \mathrm{g} \mathrm{As} \mathrm{m}^{-3}$ with addition of As(III) in soils (ESI, Fig. S8 $\dagger$ ). The proposed coupling is used in our laboratory to analyse routinely volatile As in different natural gases. It is not the aim of this paper to discuss the occurrence of arsines in the soil environment and its environmental impact. Interested readers are referred to our future papers.

\section{Acknowledgements}

We are grateful to Beate Huhle (University of Bayreuth) for providing data of arsine and methyl arsine concentrations from the headspace of wetland soil incubations. Financial support of J.-H.H. comes from Swiss National Science Foundation PZ00P2_142232.

\section{References}

1 A. Mestrot, J. Feldmann, E. M. Krupp, M. S. Hossain, G. Roman-Ross and A. A. Meharg, Environ. Sci. Technol., 2011, 45, 1798-1804.

2 H. Mukai, Y. Ambe, T. Muku, K. Takeshita and T. Fukuma, Nature, 1986, 324, 239-241.
3 S. Tamaki and W. T. Frankenberger, Rev. Environ. Contam. Toxicol., 1992, 124, 79-110.

4 D. C. Chilvers and P. J. Peterson, in Lead, Mercury, Cadmium and Arsenic in the Environment, ed. T. C. Hutchinson and $\mathrm{K}$. M. Meema, John Wiley \& Sons, 1987, vol. 31, pp. 279301.

5 R. Jakob, A. Roth, K. Haas, E. M. Krupp, A. Raab, P. Smichowski, D. Gomez and J. Feldmann, J. Environ. Monit., 2010, 12, 409-416.

6 D. J. Vaughan, Elements, 2006, 2, 71-75.

7 J. Feldmann, R. Grumping and A. V. Hirner, Fresenius' J. Anal. Chem., 1994, 350, 228-234.

8 K. Haas and J. Feldmann, Anal. Chem., 2000, 72, 4205-4211.

9 A. Mestrot, M. K. Uroic, T. Plantevin, M. R. Islam, E. M. Krupp, J. Feldmann and A. A. Meharg, Environ. Sci. Technol., 2009, 43, 8270-8275.

10 J. Feldmann and A. V. Hirner, Int. J. Environ. Anal. Chem., 1995, 60, 339-359.

11 J. Kösters, J. Hippler, R. A. Diaz-Bone and A. V. Hirner, J. Anal. At. Spectrom., 2005, 20, 996-999.

12 R. A. Diaz-Bone, M. Hollmann, O. Wuerfel and D. Pieper, J. Anal. At. Spectrom., 2009, 24, 808-814.

13 J.-H. Huang, K.-N. Hu, J. Ilgen and G. Ilgen, Food Addit. Contam., 2012, 29, 85-93.

14 J. Feldmann, L. Naels and K. Haas, J. Anal. At. Spectrom., 2001, 16, 1040-1043.

15 P. Taurkova, M. Svoboda, S. Musil and T. Matousek, J. Anal. At. Spectrom., 2011, 26, 220-223.

16 M. B. Dermani, Personal communication, University of Bayreuth, 2011.

17 D. Glindemann, G. Ilgen, R. Herrmann and T. Gollan, J. Anal. At. Spectrom., 2002, 17, 1386-1389.

18 M. Peitzsch, PhD thesis, University of Mainz, 2008.

19 E. O. Uthus, M. E. Collings, W. E. Cornatzer and F. H. Nielsen, Anal. Chem., 1981, 53, 2221-2224.

20 G. Ilgen, D. Glindemann, R. Herrmann, F. Hertel and J. H. Huang, Waste Manag., 2008, 28, 1518-1527.

21 Deutsches Institut für Normung e. V (DIN) 23645. 2008.

22 C. G. Yuan, K. G. Zhang, Z. H. Wang and G. B. Jiang, J. Anal. At. Spectrom., 2010, 25, 1605-1611. 